\title{
A FAMILY OF NECESSARY STABILITY INEQUALITIES VIA QUADRATIC FORMS
}

\author{
PRASHANT BATRA
}

Abstract. Inequalities relating three coefficients of the even or odd part of a Hurwitz-stable polynomial have been established recently via the Newton-MacLaurin inequalities, and via optimization techniques for multivariate functions on the positive orthant. From the theory of quadratic forms we derive a family of strict inequalities which includes and generalizes the known inequalities. For polynomials of higher degree quantifiable improvements are obtained. Benefit of these inequalities is low-cost instability testing for polynomials with varying coefficients.

Mathematics subject classification (2010): 15A63, 26C10, 93D09.

Keywords and phrases: Quadratic forms, Cauchy index, stability conditions, interval polynomial.

\section{REFERENCES}

[1] A. Borobia, S. Dormido, Three coefficients of a polynomial can determine its instability, Linear Algebra and its Appl., 338 (2001), 67-76.

[2] F.R. Gantmacher, Matrizentheorie, VEB Deutscher Verlag der Wissenschaften, Berlin, 1986.

[3] A. HURWITZ, Über die Bedingungen, unter welchen eine Gleichung nur Wurzeln mit negativen reellen Theilen besitzt, Mathematische Annalen, 46 (1895), 273-284.

[4] M.G. Krein, M.A. NAimark, The Method of Symmetric and Hermitian Forms in the Theory of the Separation of the Roots of Algebraic Equations, Linear and Multilinear Algebra, 10 (1981), 265-308.

[5] M.M. MARden, The Geometry of Polynomials, AMS, Providence, Rhode Island, second edition, 1966.

[6] Q.I. Rahman, G. SchmeIsser, Analytic Theory of Polynomials, Oxford University Press, Oxford, UK, 2002.

[7] X. YAnG, Necessary conditions of Hurwitz polynomials, Linear Algebra and its Appl., 359 (2003), 21-27.

[8] X. YAnG, Some necessary conditions for Hurwitz stability, Automatica, 40 (2004), 527-529. 